\title{
Respostas correlacionadas do algodoeiro com a seleção para a coloração da fibra(1)
}

\author{
Luiz Paulo de Carvalho(2) e José Wellington dos Santos ${ }^{(3)}$
}

\begin{abstract}
Resumo - Os constantes trabalhos de melhoramento com o algodão de fibra branca produziram cultivares superiores com fibra de melhor qualidade tecnológica do que a do algodão de fibra colorida. O objetivo deste trabalho foi avaliar o efeito da seleção para diferentes graus de coloração, nas características tecnológicas de fibra do algodoeiro herbáceo em progênies $\mathrm{F}_{5}$ do cruzamento de cultivares adaptadas, de fibra branca, com materiais introduzidos, portadores de genes conhecidos para cor marrom e verde. A maioria dos caracteres de fibra se correlacionou negativamente com a coloração da fibra, e as respostas correlacionadas diminuíram à medida que se intensificou a seleção para cores mais escuras da fibra.
\end{abstract}

Termos para indexação: Gossypium hirsutum, progênie, cor, melhoramento de planta.

\section{Correlated responses on cotton fiber traits with the selection for fiber color}

\begin{abstract}
Constant breeding works with the white fiber cotton developed higher cultivars that show better fiber quality than the colored lint ones. The objective of this work was to evaluate the effect of the selection for different color grades on the fiber quality of upland cotton in $\mathrm{F}_{5}$ progenies from the crossing between adapted white fiber cultivars and exotic green and brown germplasm bearing known genes for these lint colors. Most of the fiber traits were negatively correlated with the color fiber and the correlated responses decreased when the selection was made for more intense color of the fiber.
\end{abstract}

Index terms: Gossypium hirsutum, progeny, color, plant breeding.

\section{Introdução}

O algodão colorido é quase tão antigo quanto o branco, conforme amostras encontradas em escavações no Peru que remontam a 2.500 a.C.; as de algodão branco originárias do Pasquistão datam de 2.700 a.C. (Gulatti \& Turner, 1928). Os algodões silvestres, em sua maioria, possuem fibra colorida de marrom em várias tonalidades, embora não possuam fibra fiável. Os trabalhos de melhoramento com o algodão branco desde a metade do século 20 produziram cultivares superiores e adaptadas e acentuaram a diferença entre os caracteres de importância econômica dos dois tipos de algodão, já que o colorido foi muito pouco estudado nesse período.

\footnotetext{
(1) Aceito para publicação em 9 de setembro de 2002.

(2) Embrapa-Centro Nacional de Pesquisa de Algodão (CNPA), Caixa Postal 174, CEP 58107-720 Campina Grande, PB. Bolsista do CNPq. E-mail: 1paulo@cnpa.embrapa.br

(3) Embrapa-CNPA. E-mail: jwsantos@cnpa.embrapa.br
}

Recentemente tem crescido o interesse no cultivo do algodão de fibra colorida e, por conseguinte, trabalhos de melhoramento com o objetivo de produzir cultivares de fibra colorida e de boa qualidade tecnológica estão sendo realizados.

A cor da fibra, apesar de controlada geneticamente, possui um componente ambiental, como tipo de solo, conteúdo de minerais do solo e luz solar, que determina a sua manifestação fenotípica (Natural..., 1992).

O línter e a fibra dos algodões tetraplóides ocorrem em cores que vão do branco a várias tonalidades de verde e marrom, com relatos na literatura dos genes responsáveis por essas cores (Ware, 1932; Harland, 1935; Kohel, 1985). Os algodões de fibra colorida normalmente possuem fibra de qualidades tecnológicas inferiores.

O objetivo deste trabalho foi avaliar o efeito da seleção para coloração da fibra nas características tecnológicas da fibra do algodoeiro herbáceo. 


\section{Material e Métodos}

Em 1997 iniciou-se um programa de melhoramento com o objetivo de produzir cultivares de algodão herbáceo (Gossypium hirsutum L. r. latifolium (Hutch.)) de fibra colorida e boa qualidade tecnológica. Para isso, três cultivares de fibra branca já adaptadas à Região Nordeste do Brasil, CNPA 7H, CNPA Precoce 3 e CNPA Precoce 2, com características de fibra de bom padrão tecnológico, foram cruzadas com materiais exóticos de G. hirsutum, sendo um de fibra verde, Arkansas Green, portador do mutante dominante $\mathrm{Lg}$ para cor verde, e outro portador de um gene para cor marrom. Os cruzamentos, realizados em casa de vegetação, em Campina Grande, $\mathrm{PB}$, foram os seguintes: CNPA 7H x Marrom; CNPA Precoce 3 x Marrom; CNPA Precoce 2 x Arkansas Green. A partir da geração $F_{2}$ de cada cruzamento, iniciou-se um programa de seleção genealógica cujo principal critério de seleção foi o grau de intensidade da cor, já que nas gerações segregantes apareciam plantas com várias intensidades de marrom e verde. Procedeu-se, desta maneira, até não haver mais segregação dentro de cada intensidade de cor. Durante o processo procurava-se também transferir para a geração seguinte plantas ou progênies com melhores características de fibra. As gerações segregantes foram realizadas nos municípios mineiros de Uberlândia e Capinópolis, em 1999 e 2000.

Nos cruzamentos envolvendo as cultivares CNPA 7H e CNPA Precoce 3, foram obtidos, respectivamente, 24 e 13 progênies $\mathrm{F}_{5}$ com diferentes tonalidades de marrom. Os cruzamentos com a cultivar CNPA Precoce 2 originaram 20 progênies com diferentes tonalidades de verde. Em 2001, as 24 progênies marrons foram avaliadas em relação aos caracteres de fibra em um ensaio em blocos casualizados, com duas repetições, o mesmo acontecendo com as 13 progênies marrons, em um segundo ensaio, com três repetições. As 20 progênies verdes foram avaliadas em um terceiro ensaio, em blocos ao acaso, com duas repetições. Os ensaios foram realizados em Barbalha, CE, e a área útil da parcela foi constituída por uma fileira de $5 \mathrm{~m}$ de comprimento no espaçamento de $1 \mathrm{~m}$ entre linhas e 50 plantas por linha. Em todos os ensaios foram avaliadas as características de fibra, e no ensaio envolvendo progênies da cultivar CNPA Precoce 3 também avaliou-se o rendimento das progênies.

As análises das características de fibra foram realizadas em amostras de 20 capulhos retirados por parcela, em HVI (HighVolume Instruments). Esse material serviu, ainda, para determinar visualmente a intensidade da cor nas progênies, por meio de escala de notas que variaram de 1 a 4 . Para o algodão de fibra marrom: a nota 1 correspondeu ao branco; a nota 2, ao creme; a nota 3, ao marrom-claro; e a nota 4, ao marrom-escuro. Para o algodão de fibra verde: a nota 1 correspondeu ao branco; a nota 2, ao quase branco; a nota 3 , ao verde-claro; e a nota 4 , ao verde.

Correlações genotípicas entre a intensidade da cor e as características da fibra foram estimadas conforme Mode \& Robinson (1959) e Kemptorne (1969). Estimaram-se também as herdabilidades baseadas na média das progênies, considerando-se aleatório o efeito destas, já que elas permitem generalizar os dados em uma população de progênies de algodoeiro herbáceo. Foram calculadas, ainda, as respostas correlacionadas dos caracteres de fibra quando se praticava a seleção para as três classes de cor (notas 2, 3 e 4). As respostas correlacionadas foram calculadas usando-se a expressão: $\mathrm{GS}_{\mathrm{j}(\mathrm{i})}=\mathrm{DS}_{\mathrm{j}(\mathrm{i})} \cdot \mathrm{h}^{2}{ }_{(\mathrm{j})}$, em que: $\mathrm{GS}_{\mathrm{j}(\mathrm{i})}$ é o ganho de seleção no caráter j quando se pratica a seleção no caráter i; $\mathrm{DS}_{\mathrm{j}(\mathrm{i})}$ é o diferencial de seleção indireto; $\mathrm{h}^{2}{ }_{(\mathrm{j})}$ é a herdabilidade do caráter j no sentido amplo calculada com base na média das progênies.

Em cada experimento, o diferencial de seleção foi calculado selecionando-se todas as progênies com notas 2, 3 e 4 , em relação à coloração da fibra. Os dados foram submetidos à análise de variância e foram avaliados os contrastes entre a média da testemunha de fibra branca em cada ensaio e a média das famílias com determinado grau de coloração, pelo teste de Tukey a $1 \%$ de probabilidade.

\section{Resultados e Discussão}

À exceção do alongamento e finura, que não se mostraram correlacionados, os demais caracteres se correlacionaram negativamente com a cor marrom da fibra (Tabela 1). Foram observadas correlações ne- 
gativas significativas da cor marrom com a porcentagem de fibra, peso de capulhos, resistência e comprimento. O comprimento mostrou correlação negativa, apesar de não-significativa com a cor verde da fibra, e o alongamento não mostrou correlação com essa cor.

Esses dados revelam a dificuldade que se pode ter quando se deseja intensificar a cor da fibra das cultivares e ao mesmo tempo melhorar as características tecnológicas. Isso pôde ser evidenciado quando foram selecionadas todas as progênies com fibra de determinada cor e calculadas as respostas indiretas nos demais caracteres de fibra. Nas progênies derivadas de CNPA 7H, as respostas nos demais caracteres aumentaram à medida que se selecionou em relação às cores mais claras, do marrom-escuro ao creme (Tabela 2). As maiores respostas indiretas negativas foram obtidas na resistência de fibra, no comprimento e no peso de capulhos. Quanto aos dois caracteres com os maiores ganhos indiretos negativos, resistência e comprimento, a resposta foi positiva quando se passou a selecionar em relação à cor mais clara, creme. Nos demais caracteres, a resposta também aumentou à medida que se selecionaram fibras mais claras.

Considerando-se as progênies de CNPA Precoce 3 e a cor marrom, os dados foram semelhantes. As maiores respostas indiretas negativas foram no comprimento, na resistência e no peso de capulhos; a resposta indireta passou a ser positiva quando a seleção se deslocou para a cor mais clara, creme.

O línter e a fibra dos algodões tetraplóides ocorrem em cores que vão do branco a várias tonalidades de verde e marrom. Harland (1935) determinou que a cor marrom da fibra era condicionada por dois locos independentes, $\mathrm{Lc}_{1}$ e $\mathrm{Lc}_{2}$, em G. hirsutum e

Tabela 1. Correlações genotípicas entre o grau de coloração da fibra e suas características tecnológicas em progênies de algodão derivadas do cruzamento das cultivares de fibra branca CNPA 7H, CNPA Precoce 3 e CNPA Precoce 2 com genótipos de fibra marrom e verde.

\begin{tabular}{|c|c|c|c|c|c|c|c|}
\hline Fibra $(\%)$ & $\begin{array}{c}\text { Peso do } \\
\text { capulho }(\mathrm{g})\end{array}$ & $\begin{array}{c}\text { Finura } \\
\text { (micronaire) }\end{array}$ & $\begin{array}{l}\text { Resistência } \\
\text { (gf/tex) }\end{array}$ & $\begin{array}{c}\text { Comprimento } 2,5 \% \\
(\mathrm{~mm})\end{array}$ & $\begin{array}{c}\text { Uniformidade } \\
(\%)\end{array}$ & $\begin{array}{c}\text { Alongamento } \\
(\%)\end{array}$ & $\begin{array}{c}\text { Rendimento } \\
(\mathrm{kg} / \mathrm{ha})\end{array}$ \\
\hline \multicolumn{8}{|c|}{ Linhagens derivadas de CNPA 7H (marrom) } \\
\hline$-0,28^{\text {ns }}$ & $-0,47^{*}$ & $0,02^{\mathrm{ns}}$ & $-0,78^{* *}$ & $-0,79^{* *}$ & $-0,56^{* *}$ & $0,14^{\mathrm{ns}}$ & - \\
\hline \multicolumn{8}{|c|}{ Linhagens derivadas de CNPA Precoce 3 (marrom) } \\
\hline$-0,58^{*}$ & $-0,67^{* * *}$ & $-0,12^{\mathrm{ns}}$ & $-0,91^{* *}$ & $-0,92^{* *}$ & $-0,44^{\mathrm{ns}}$ & $0,32^{\text {ns }}$ & $-0,48^{\mathrm{ns}}$ \\
\hline \multicolumn{8}{|c|}{ Linhagens derivadas de CNPA Precoce 2 (verde) } \\
\hline$-0,90^{* *}$ & $-0,47^{*}$ & $-0,65^{*}$ & $-0,54^{*}$ & $-0,40^{\mathrm{ns}}$ & $-0,49^{*}$ & $0,22^{\mathrm{ns}}$ & - \\
\hline
\end{tabular}

Tabela 2. Ganhos de seleção diretos em relação à cor da fibra e indiretos em relação a características tecnológicas, em porcentagem da média, quando a seleção foi praticada na intensidade da cor da fibra em progênies de algodão das cultivares CNPA 7H, CNPA Precoce 3 e CNPA Precoce 2.

\begin{tabular}{|c|c|c|c|c|c|c|c|c|c|}
\hline Caráter selecionado & Cor $(\%)$ & Fibra $(\%)$ & $\begin{array}{c}\text { Peso do } \\
\text { capulho (g) }\end{array}$ & $\begin{array}{c}\text { Finura } \\
\text { (micronaire) }\end{array}$ & $\begin{array}{l}\text { Resistência } \\
\text { (gf/tex) }\end{array}$ & $\begin{array}{l}\text { Comprimento } \\
2,5 \%(\mathrm{~mm})\end{array}$ & $\begin{array}{c}\text { Uniformidade } \\
(\%)\end{array}$ & $\begin{array}{c}\text { Alongamento } \\
(\%)\end{array}$ & $\begin{array}{c}\text { Rendimento } \\
(\mathrm{kg} / \mathrm{ha})\end{array}$ \\
\hline & \multicolumn{9}{|c|}{ Linhagens derivadas de CNPA 7H } \\
\hline Creme & $-23,20$ & $-0,04$ & $-0,74$ & 0,17 & 3,30 & 3,40 & 0,14 & $-1,80$ & - \\
\hline Marrom-claro & 14,24 & $-3.10^{-3}$ & 0,14 & $-1,76$ & 0,03 & $-1,67$ & $-0,21$ & 4,39 & - \\
\hline Marrom-escuro & 51,6 & $-1,73$ & $-7,60$ & 4,70 & $-14,11$ & $-10,28$ & $-8.10^{-4}$ & $-4,76$ & - \\
\hline \multirow[t]{2}{*}{ Herdabilidade } & 0,98 & 0,79 & 0,63 & 0,72 & 0,74 & 0,87 & 0,41 & 0,69 & - \\
\hline & \multicolumn{9}{|c|}{ Linhagens derivadas de CNPA Precoce 3} \\
\hline Creme & $-20,27$ & 1,06 & 3,10 & 2,50 & 3,19 & 2,60 & 0,23 & 0,19 & 2,04 \\
\hline Marrom-claro & 18,71 & $-1,80$ & $-5,31$ & $-1,90$ & $-4,40$ & $-3,80$ & $-1,40$ & 2,60 & $-2,70$ \\
\hline Marrom-escuro & 57,53 & $-1,79$ & $-6,30$ & $-1,90$ & $-5,85$ & $-9,50$ & $6.10^{-5}$ & 1,63 & $-2,70$ \\
\hline \multirow[t]{2}{*}{ Herdabilidade } & 0,98 & 0,79 & 0,77 & 0,82 & 0,63 & 0,92 & 0,72 & 0,90 & 0,27 \\
\hline & \multicolumn{9}{|c|}{ Linhagens derivadas de CNPA Precoce 2} \\
\hline Quase branco & $-21,43$ & 5,73 & $-4,62$ & $-13,57$ & 0,12 & 4,14 & 0,09 & 2,60 & - \\
\hline Verde-claro & 4,11 & $-2,14$ & $-5,26$ & $-4,11$ & $-0,18$ & $-0,60$ & $-0,17$ & 0,18 & - \\
\hline Verde & 38,37 & $-9,99$ & 2,78 & $-6,1$ & $-0,13$ & $-1,13$ & $-0,04$ & $-0,14$ & - \\
\hline Herdabilidade & 0,98 & 0,93 & 0,66 & 0,84 & 0,17 & 0,77 & 0,57 & 0,47 & - \\
\hline
\end{tabular}


G. barbadense. Uma terceira variante na cor marrom, denominada Dirty white (Dw), tem expressão equivalente a $\mathrm{Lc}_{1}$ e foi transferida de G. raimondii para G. hirsutum, de acordo com Rhyne (1960). Kohel (1985) menciona quatro locos adicionais com alelos dominantes em relação à cor marrom, denominados $\mathrm{Lc}_{3}, \mathrm{Lc}_{4}, \mathrm{Lc}_{5}$ e $\mathrm{Lc}_{6}$. No presente trabalho, o doador da cor marrom da fibra, portador de um dos genes mencionados, possuía cor escura. No entanto, foram selecionadas várias progênies $\mathrm{F}_{5}$ com diferentes tonalidades de marrom, após cessarem as segregações.

No algodão de fibra verde, as maiores respostas indiretas negativas foram na porcentagem e na finura da fibra (Tabela 2). Todos os caracteres, com exceção da finura e peso do capulho, que mostraram ganhos indiretos negativos, passaram a fornecer ganhos positivos quando a seleção foi praticada para cores quase brancas. A cor verde da fibra e do línter é condicionada por um mutante dominante $\mathrm{Lg}$, relatado em G. hirsutum (Ware, 1932). A cor da fibra e do línter determinada pelo gene Lg é bem visível durante a abertura dos capulhos, mas pode desvanecer e perder um pouco do colorido rapidamente. Uma variante alélica de Lg na qual apenas o línter permanece verde e a fibra é branca, foi determinada e designada $\operatorname{Lg}^{\mathrm{f}}$ (Kohel, 1985). Segundo o autor, a cor verde da fibra varia de intensidade de acordo com o fundo genético em que se encontra. Em certos casos, LgLg se aproxima da expressão associada a Lglg, e este, às vezes, é difícil de distinguir de lglg.

A média das progênies em cada grau de cor diferiu da testemunha de fibra branca, em relação a maioria dos caracteres (Tabela 3).

A cor da fibra, apesar de controlada geneticamente, possui fatores ambientais determinantes do fenótipo, como o tipo de solo, o conteúdo de minerais do solo e a luz solar (Natural..., 1992). No presente trabalho, a cor, determinada pelo mutante dominante $\mathrm{Lg}$, apresentou herdabilidades elevadas, em torno de 0,98 , e foi a resposta direta à seleção quanto a esse caráter alta (Tabela 2).

A principal causa da correlação genética é a pleiotropia, com as ligações genéticas sendo causa de correlações transitórias, principalmente em populações derivadas de cruzamentos divergentes (Falconer,1987). Apesar das correlações negativas entre a cor e os caracteres de fibra, existem progênies na geração $\mathrm{F}_{5}$ dos cruzamentos com fibra escura e com características tecnológicas com médias maiores. Isso evidencia que houve recombinação entre os genes controladores desses dois caracteres, sugerindo a ligação gênica como causa dessas correlações. Neste caso, os métodos de melhoramento dessas características devem maximizar a quebra de tais ligações; programas de seleção envolvendo

Tabela 3. Características tecnológicas da fibra de progênies (média) com diferentes graus de coloração marrom (derivadas da cultivar CNPA 7H) e de coloração verde (derivadas da cultivar CNPA Precoce 2) e das testemunhas de fibra branca, cultivares CNPA 7H (T1) e CNPA Precoce 3 (T2) ${ }^{(1)}$.

\begin{tabular}{|c|c|c|c|c|c|c|c|c|}
\hline \multirow[t]{2}{*}{ Característica } & \multicolumn{3}{|c|}{ Marrom $^{(2)}$} & \multirow[t]{2}{*}{$\mathrm{T} 1$} & \multicolumn{3}{|c|}{ Verde $^{(3)}$} & \multirow[t]{2}{*}{$\mathrm{T} 2$} \\
\hline & 4 & 3 & 2 & & 4 & 3 & 2 & \\
\hline Porcentagem de fibra (\%) & $36,10 \mathrm{a}$ & $36,00 \mathrm{a}$ & $35,20 \mathrm{a}$ & $38,80 \mathrm{~b}$ & $34,60 \mathrm{a}$ & $31,80 \mathrm{a}$ & $29,10 \mathrm{a}$ & $39,60 \mathrm{~b}$ \\
\hline Peso de capulho $(\mathrm{g})$ & $4,14 a$ & $4,29 a$ & $3,95 \mathrm{a}$ & $5,95 b$ & $4,20 \mathrm{a}$ & $4,20 \mathrm{a}$ & $4,70 \mathrm{a}$ & $6,30 \mathrm{~b}$ \\
\hline Finura (micronaire) & $4,04 \mathrm{a}$ & $3,99 \mathrm{a}$ & $4,53 \mathrm{a}$ & $4,45 \mathrm{a}$ & $2,70 \mathrm{a}$ & $3,10 \mathrm{a}$ & $3,00 \mathrm{a}$ & $4,40 \mathrm{~b}$ \\
\hline Resistência (gf/tex) & $23,30 \mathrm{a}$ & $23,00 \mathrm{a}$ & $19,50 \mathrm{a}$ & $28,20 \mathrm{~b}$ & $25,10 \mathrm{a}$ & $24,60 \mathrm{a}$ & $24,70 \mathrm{a}$ & $26,40 \mathrm{a}$ \\
\hline Comprimento $2,5 \%(\mathrm{~mm})$ & $27,00 \mathrm{a}$ & $25,70 \mathrm{a}$ & $23,10 \mathrm{a}$ & $29,30 \mathrm{~b}$ & $30,20 \mathrm{~b}$ & $28,30 \mathrm{a}$ & $28,20 \mathrm{a}$ & $30,30 \mathrm{~b}$ \\
\hline Uniformidade $(\%)$ & $83,00 \mathrm{a}$ & $82,40 \mathrm{a}$ & $82,40 \mathrm{a}$ & $85,20 \mathrm{~b}$ & $84,10 b$ & $83,70 \mathrm{a}$ & $83,90 \mathrm{~b}$ & $85,00 \mathrm{~b}$ \\
\hline Alongamento (\%) & $8,78 \mathrm{a}$ & $9,72 b$ & $8,70 \mathrm{a}$ & $8,65 \mathrm{a}$ & $10,60 \mathrm{a}$ & $10,10 \mathrm{a}$ & $10,00 \mathrm{a}$ & $9,80 \mathrm{a}$ \\
\hline Rendimento $(\mathrm{kg} / \mathrm{ha})^{(4)}$ & $1.448 \mathrm{a}$ & $1.826 \mathrm{a}$ & $1.312 \mathrm{a}$ & $1.561 \mathrm{a}$ & - & - & - & - \\
\hline
\end{tabular}

${ }^{(1)}$ Cada par de médias, uma da progênie e outra da testemunha, seguidas da mesma letra, não diferem entre si pelo teste de Tukey a $1 \%$ de probabilidade; dentro da cor marrom, as médias de uniformidade dos graus 4,3 e 2 e a média de alongamento do grau 3 foram comparadas a 5\% de probabilidade. ${ }^{(2)} 4$ : marrom-escuro; 3: marrom-claro; 2: creme. ${ }^{(3)} 4$ : verde; 3: verde-claro; 2: quase branco. ${ }^{(4)}$ Rendimento: estimado do ensaio de progênies derivadas da cultivar CNPA Precoce 3. 
intercruzamento seriam preferíveis, seguindo esquemas de seleção recorrente que permitissem pequenos ganhos na direção da combinação desejada. Os índices de seleção, conforme Al-Jibouri et al. (1958) ao trabalhar com algodão de fibra branca apresentando correlações genéticas negativas, podem ser de grande importância nessas condições.

\section{Conclusões}

1. Os caracteres da fibra e o rendimento do algodoeiro herbáceo correlacionam-se negativamente com a coloração da fibra, ou seja, quanto maior é o grau de coloração, menores são as médias nos vários caracteres.

2. As respostas correlacionadas nas características de fibra diminuem, isto é, passam de valores positivos para negativos quando se intensifica a seleção com relação à fibra mais colorida.

3. As médias de todos os caracteres das cultivares de fibra branca são sempre maiores que as das progênies com diferentes graus de coloração da fibra.

\section{Referências}

AL-JIBOURI, A. A.; MILLER, P. A.; ROBINSON, H. J. Genotypic and environmental variances and covariances in an upland cotton cross of interspecific origin. Agronomy Journal, Madison, v. 50, p. 633-636, 1958.

FALCONER, D. S. Introdução à genética quantitativa . Viçosa, MG: UFV, 1987. 210 p.

GUlatTi, A. M.; TURNER, A. J. A note on the early history of cotton. Bombaim: Indian Central Cotton Committee, 1928. (Technical Laboratory Bulletin, 17).

HARLAND, S. C. The genetics of cotton. XIV. The inheritance of brown lint in New World cottons. Journal Genetic, Bangalore, v. 31, p. 27-37, 1935.

KEMPTORNE, O. An introduction to genetic statistics. Ames: Iowa State University Press, 1969. 545 p.

KOHEL, R. J. Genetic analysis of fiber color variants in cotton. Crop Science, Madison v. 25, n. 5, p. 793-797, 1985.

MODE, C. J.; ROBINSON, H. J. Pleiotropism and genetic variances and covariances. Biometrics, Washington, v. 15, p. 518-537, 1959.

NATURAL colors of cotton. ICAC Recorder, Washington, v. 10, n. 4, p. 3-5, Dec. 1992.

RHYNE, C. L. Linkage studies in Gossypium. II. Altered recombination values in a linkage group of allotetraploid G. hirsutum L. as a result of transferred diploid species genes. Genetics, Stanford, v. 45, p. 673-681, 1960.

WARE, J. O. Inheritance of lint colors in upland cotton. Journal of the American Society of Agronomy, Madison, v. 24, p. 550-562,1932. 